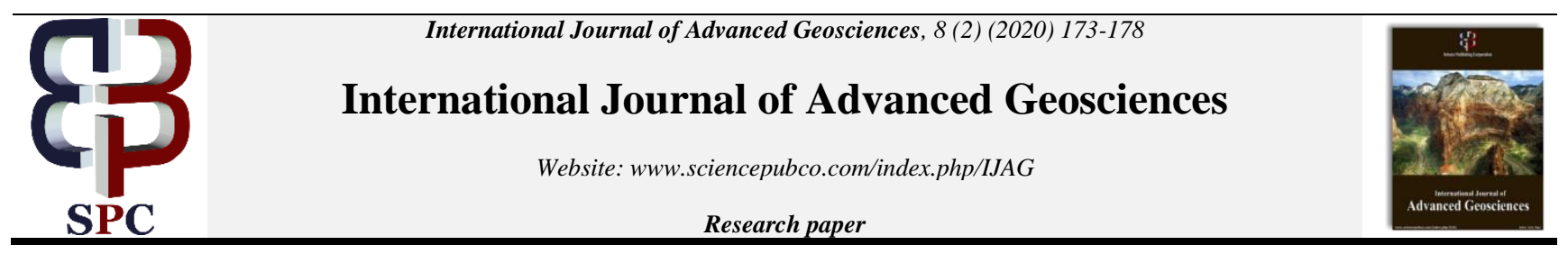

\title{
Salinity variation of south-western coastal region of Bangladesh in response to discharge from an upstream river
}

\author{
Md. Shibly Anwar ${ }^{1}$, Md. Zakir Hasan ${ }^{1}$, Kalimur Rahman ${ }^{1 *}$ \\ ${ }^{1}$ Assistant Professor, Department of Civil Engineering, Dhaka University of Engineering \& Technology, Gazipur, Bangladesh \\ *Corresponding author E-mail: kalimur_ce@duet.ac.bd
}

\begin{abstract}
Long term variation in upstream water flow through the Ganges-Gorai river are affecting the salinity levels of south-western coastal region of Bangladesh. Salinity data for the Rupsha river was collected for several years to demonstrate the historical changes of salinity level in the south-western coastal region. Furthermore, discharge data of the Ganges and Gorai river were also collected to discuss the effect of upstream discharge on the variation of salinity level. This study also collected water and soil samples from different places of this region to measure the salinity level and compare the values with the standard ones. A decreasing trend in dry season Ganges-Gorai river flow was observed after the initiation of the Farakka barrage in 1975. Consequently, the south-western region underwent high salinity level. The Ganges sharing treaty in 1996 and dredging of the Gorai riverbed (GRRP-I and GRRP-II) in 1999 and in 2012 helped the region to recover from high salinity level for a certain period. The salinity level of the collected water samples was in alarming level but soil sample was not in so frightening condition in 2015. Results suggested that to maintain the salinity level of south-western region within the acceptable limit for drinking, fisheries, and cultivation purposes, approximately $80 \mathrm{~m}^{3} / \mathrm{s}$ Gorai river discharges required at dry season. To do that, it is necessary to ensure $1200 \mathrm{~m}^{3} / \mathrm{s}$ discharge through the Ganges river at the Hardinge Bridge point. To protect the vital south-western region, it becomes necessary to optimize flow augmentation in the Ganges-Gorai river and to continue the further phases of restoration project in the future.
\end{abstract}

Keywords: Bangladesh; Electrical Conductivity; Ganges River; Salinity; Discharge.

\section{Introduction}

Bangladesh is mostly familiar as a South Asian low-lying, riverine country with a high density of population. According to World Bank, the population of Bangladesh is above 161 million with a density of 1203 people per square kilometer in 2015 . The country is formed by a delta plain at the confluence of three major rivers (i.e., the Ganges, the Brahmaputra, the Meghna (GBM), and their tributaries).

Three sides of Bangladesh are surrounded by India and part of the south-east side is bordered by Myanmar and on the south along a 710 $\mathrm{km}$ long coastline by the Bay of Bengal. The coastal area of Bangladesh is divided into three distinct regions namely, western, central, and eastern coastal zones (Fig. 1).

The western part comprises very low and flat, semi active delta, and is crisscrossed by numerous channels and creeks. The south-western region is mostly covered by Khulna and Satkhira districts. The western coastal area covers maximum part of the Sundarbans, largest single trace of mangrove forest. This south-western area is entirely plane land. The agricultural and fisheries activities in this area are widely spread. This area contributes for securing national food demand i.e. rice, jute, fruits fish etc., economy, and regional ecological balance. There are several issues and problems (i.e., salinity, cyclone, flood etc.) are hindering the development and peace of the western coastal area of Bangladesh.

The Ganges river (Fig. 1) plays an important role to supply the fresh water to the south-western region of Bangladesh. The Gorai river (Fig. 1) is one of the major tributaries of the Ganges river to supply the upstream Ganges water to the river, channel, and creecks of the south western coastal region, especially in the dry season. Some anthropogenic activities, i.e., construction of Farakka Barrage at India in 1975 on the Ganges river upstream, $16.5 \mathrm{~km}$ from Bangladesh border as well as disappearance of Ganges dependent small rivers and lakes causes the lack of fresh water supply this region. As a result, the salinity level of the western coastal region of Bangladesh is rising drastically [1]. Several studies reported other possible reasons for the changes of salinity level in the western region i.e., local/ regional man made activities (shrimp farming, destruction of forestry), land or river bank erosion, siltation, water logging as well as natural causes i.e., sea level rise, cyclones, storm surges, and floods [2], [3].

In Bangladesh, it is perceived that the diversion from Farakka has raised salinity levels, contaminated hydrology, agriculture, aquaculture and fisheries, hindered navigation, and posed a threat to water quality and public health at the south-western coastal area [4]. Lower levels of soil moisture during dry season along with increased salinity can also led to desertification. Coastal surface and ground water are undergoing salty condition therefore people are being deprived of fresh water. Salinity also hampers the coastal peoples' livelihood and health condition. This increased salinity also causes degradation of the Sundarban trees and ecosystem and restrains the crop yield and production 
of the agricultural land of this region. The coastal indigenous fish culture is going to damage, and livestock conditions are greatly hampered due to higher degree of salinity. Several studies reported about the undesirable effects of the high-level salinity of the western coastal zone of Bangladesh [1], [5], [6].

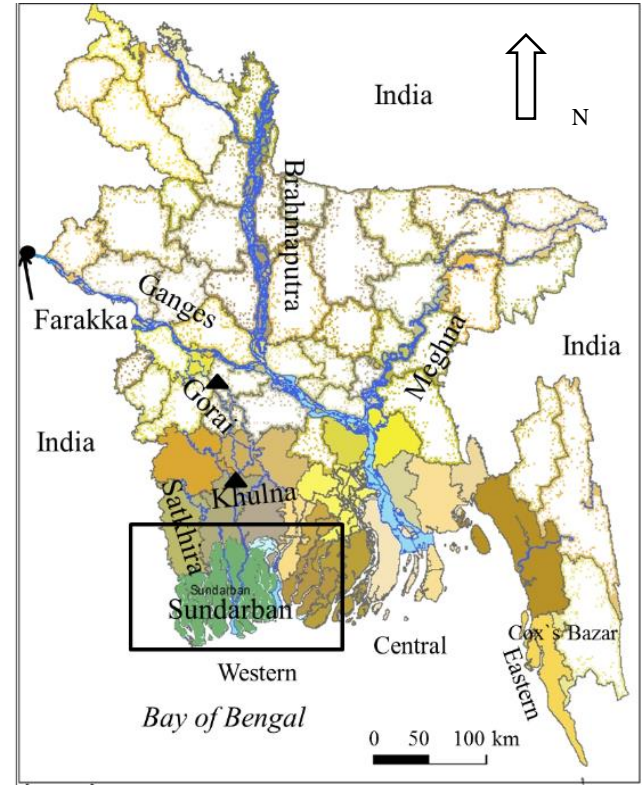

Fig. 1: Coastal zones of Bangladesh with the major rivers.

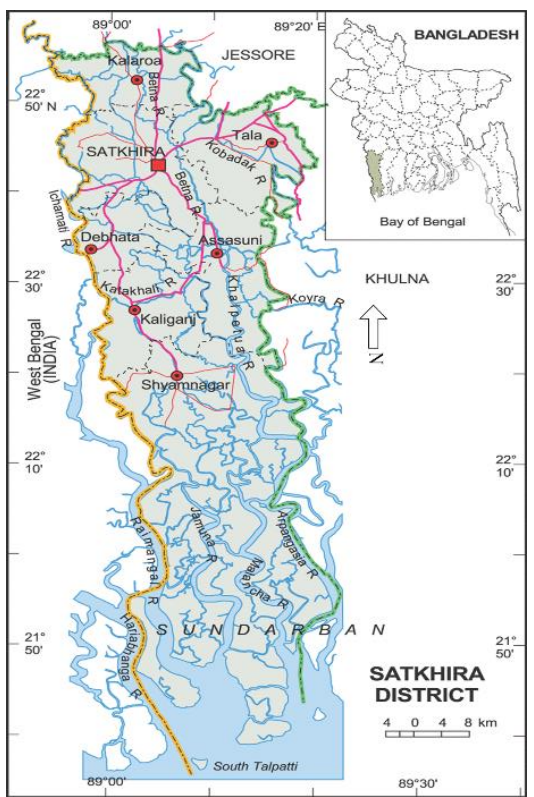

Fig. 2: Satkhira District Map Showing Assasuni and Syamnagar Upazila

Due to the 30-year treaty between India and Bangladesh on sharing the Ganges water (signed on 12 December 1996) and the pilot dredging project named the Gorai river Restoration Project (Phase-1) for the Gorai river (Fig. 1) in 1998 and 1999, a significant increase in freshwater flow has been achieved with a corresponding decrease in salinity around the south-western region at the early of the 2000s. Bangladesh Water Development Board (BWDB) under the Ministry of water resources again implemented a project "Gorai river Restoration Project (Phase-2)" (GRRP-II) during November 2009 to 2012. Both projects aimed to prevent environmental degradation in the south-western region especially Khulna, Satkhira district, the coastal belt and in Sundarbans [6]. It is expectedly achieved by increasing the dry-season inflow volume from Ganges river and maintaining the water volume by dredging at the inflow point, improving the system to effectively utilize the inflowing freshwater, and increasing the organizational power, based on sustainability, to manage and maintain the restored water systems.

It is a vast issue to discuss about salinity variation and its negative impact on different environmental parameters. Observing the historical changes on the Ganges and Gorai river discharge, the study objectives has been set as (i) to identify the long term variation of the Ganges and Gorai river discharge, (ii) to find out the changes in salinity level on south-western region of Bangladesh, and (iii) to determine the present soil and water salinity at three locations of western-region and compare the values with standard tolerable values for dirking water, fisheries and crops productions. 


\section{Data collection and methodology}

River discharge data and river water salinity data were collected from Bangladesh Water Development Board (BWDB) to observe the seasonal and long-term variation of river discharge and changes of salinity level at the South-western coastal region of Bangladesh. Further to measure the present water and soil salinity level a field visit was conducted to collect water and soil sample from three villages located at western coast region.

\subsection{River discharge and salinity data}

River discharge data for the Ganges river at Hardinge Bridge point (Station ID SW90), Iswardi, Pabna (Fig.1), has been collected for the year 1970 to 2015 for station. The collected daily data were averaged and made mean monthly data for the time. Further the mean monthly data has been rearranged for dry (January- May) and wet (June to September) season. Total 552 months data were collected among them $3.26 \%$-month data has been missing for dry season (Jan- May) and $1.8 \%$ for wet season (Jun-Sept).

The Gorai river discharge data for 1983 to 2015 were collected for the Gorai Railway Bridge station (ID SW99). There are 396 months data. Each month contains one or two data in 30 days. Among the monthly data only $0.06 \%$ monthly data has been missing for dry season and about $0.02 \%$ data has been missing for wet season.

The water salinity data of the Rupsha river (Fig.1) at Khulna Station (ID SW241) were collected for the period of 1969 to 2015. Each month data contains two, three or multiple data values. The data were averaged and converted as a monthly mean value. There are some years (i.e., 1971-1975, 1981, 1990, and 2012) which do not have any supplied data. Among the 480 months data, about $0.06 \%$ data has been missing for dry season and about $87 \%$ data has been missing for wet season. That is one of the reasons we did not consider the wet season salinity data in our study. From October to December there is no data has been provided.

\subsection{Field survey}

A field survey was conducted at three villages in western coastal region on 10th -12th March 2015 to collect soil and water samples. The selected villages are Chakla, Diglarait and Padma Pukur village (as shown in Fig. 2), in Assasuni and Shyamnagar upazila under Satkhira district. These villages are bounded by two rivers: the Kapatakha and Kholpetua (Fig. 2). These rivers are connected to Bhairab through the Betna river. Bhairab is only one source of fresh water supply to the study area, which is fed by the Ganges and Gorai river. In the dry season, these rivers are suffering from receiving sufficient fresh water from the upstream Ganges river as a result the salinity level reach at very high level.

The water and soil sample were collected randomly from different locations of the study area. The water sample was collected from deep tube well, shallow tube well, pond, canal, river, and crop field. The soil samples were also collected randomly from paddy field, canal, and pond. The detail descriptions of sample location are given in the Table 1 . The collected soil samples were bought to Dhaka University of Engineering \& Technology (DUET) environmental lab to measure the salinity level by measuring electrical conductivity (EC) level of soil and water samples. The water samples were tested by $\mathrm{HACH}$ sensor ${ }^{\mathrm{TM}} 156$ portable multi-meter.

Table 1: Location of Collected Water and Soil Samples

\begin{tabular}{lll}
\hline Sample Location & SL. No. & Description of Sample \\
\hline \multirow{3}{*}{ Crop fields (i) } & 1 & Salinity affected crops field Chakla \\
& 2 & Salinity affected land Diglarait \\
& 3 & Salinity affected land Padma Pukur \\
Crop fields (ii) & 4 & Padma Pukur \\
& 5 & Diglarait \\
Canal soil & 6 & Chakla \\
Pond soil & 7 & Chakla \\
\hline
\end{tabular}

\section{Results}

The available river discharge data for the Ganges and Gorai river and EC (Electrical Conductivity) level data of the Rupsha river has been analyzed to observe the change of salinity level at the western coastal zone of Bangladesh with the historical variation of upstream river discharge. Field soil and water samples were also taken into consideration to understand the present salinity condition of this region.

\subsection{Variation of the Ganges and Gorai river discharge}

Fig. 3 shows the historical variation of the Ganges and Gorai river discharge at dry and wet seasons mentioning the different activities happened on these rivers. From the figure, it is evident that after the construction of the Farakka barrage, discharge in both the rivers decreased gradually at dry and wet seasons. Even though, the discharge of the Gorai river reached almost zero level during the year 19881995 in dry season. After the sharing treaty in 1996 and GRRP-I in 1999, discharge mode turned into increasing mostly in dry season. Hereafter in 2012, GRRP-II has been implemented and the projects outcome shows positive results to increase the river discharge.

Fig. 4 represents the salinity variation of the Rupsha river, representing the salinity variation of south-western coastal region at dry season with changing of the Gorai river discharge. Before the sharing treaty, the salinity level of this region became very high as the Gorai river was receiving very little amount of water and it was almost zero to feed the western zones river. The implementation of GRRP-I and GRRPII project after the sharing treaty helps to reduce salinity level of this reason for a certain period.

Linear relationship between the Ganges and Gorai river discharges as well as the Gorai river discharge and salinity at dry season has been shown in Fig. 5. The correlation shows that in dry season, the Gorai river discharge has positive correlation with the Ganges river discharge at statistically 95\% confidence level. Thus, the Gorai river discharge solely depends on the Ganges river flows at dry season. In the wet season, the study did not get significant correlation between the discharges of theses rivers. In wet season the Gorai river discharge may not only depends on the upstream Ganges river flow but also rainfall may be a dominating factor to supply water through the Gorai river. 


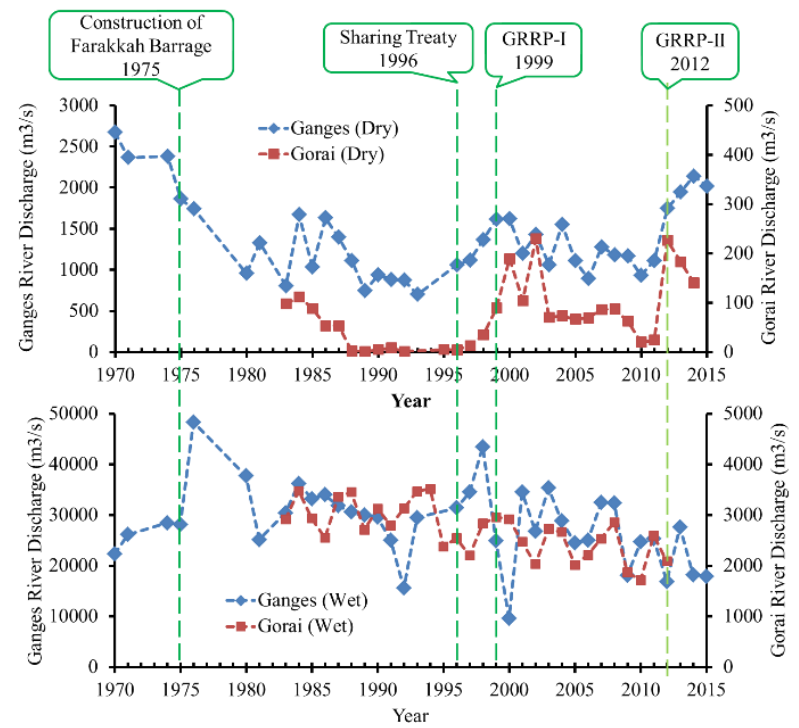

Fig. 3: Historical Discharge Variation of the Ganges and Gorai River.

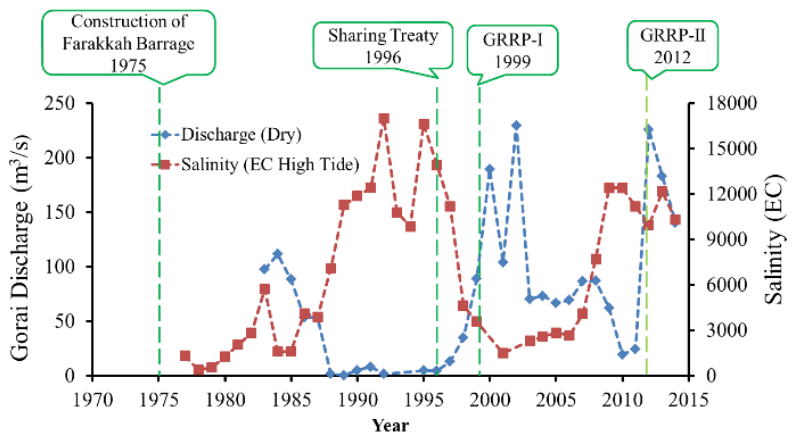

Fig. 4: Historical Variation of the Gorai River Discharge and the Rupsha River Salinity.

Further, the salinity of the Rupsha river has statistically significant negative correlation with the Gorai river discharge at dry season. The result indicates that salinity variation of the south-western region of Bangladesh dependable on the variation of the Ganges and Gorai river flow. Unavailability of wet season salinity data restricted us to make correlation with wet season discharge. Though, the salinity at wet season may also depend on the rainfall variations rather than solely depends on upstream discharge.
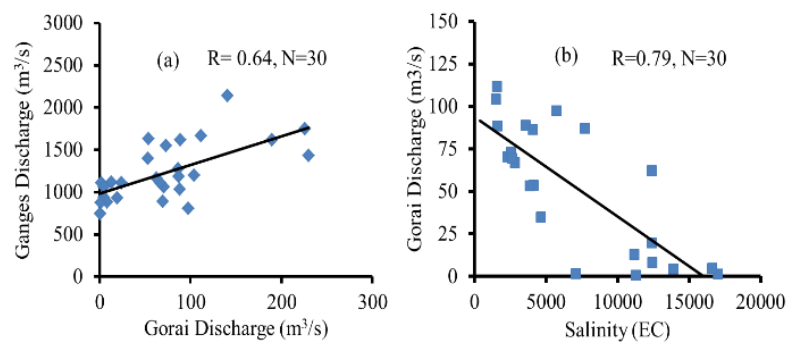

Fig. 5: Correlation of (A) the Ganges and Gorai River Discharge, (B) the Gorai River Discharge and the Rupsha River Salinity at Dry Season.

\subsection{Present water and soil salinity}

The Laboratory test result shown in Fig. 6 indicates that the salinity level of pond, canal, and irrigation water from shallow depth reached at much higher values with compared to the acceptable limits for the irrigation, drinking purposes and for the survival of the local fish. In case of irrigation standard, tolerable limit of EC is $1200 \mu \mathrm{S} / \mathrm{cm}$ [7], for drinking it is $1000 \mu \mathrm{S} / \mathrm{cm}$ [8] and for local fish it is $700 \mu \mathrm{S} / \mathrm{cm}$ [9],[10]. So deep tube well may be less harmful, but the surface and shallow depth water may be very harmful for drinking, irrigation, and local fishing purpose.

The soil salinity test graph as shown in Fig. 7 outlines that; the soil is in non-saline to slightly saline condition. Rice yields decline when the salinity of irrigation water is higher than 2.0 to $5 \mathrm{dS} / \mathrm{m} \mathrm{[11]} \mathrm{and} \mathrm{other} \mathrm{crops} \mathrm{have} \mathrm{different} \mathrm{tolerable} \mathrm{limits.} \mathrm{Salinity} \mathrm{values} \mathrm{of} \mathrm{collected}$ soil samples are within the standard limit. So, in this type of soil, the cultivation of crops may be not so harmful. Though, salinity tolerance of a crop is a complex function of soil type, solution composition, crop type, crop variety, and the timing of salinity stress. 

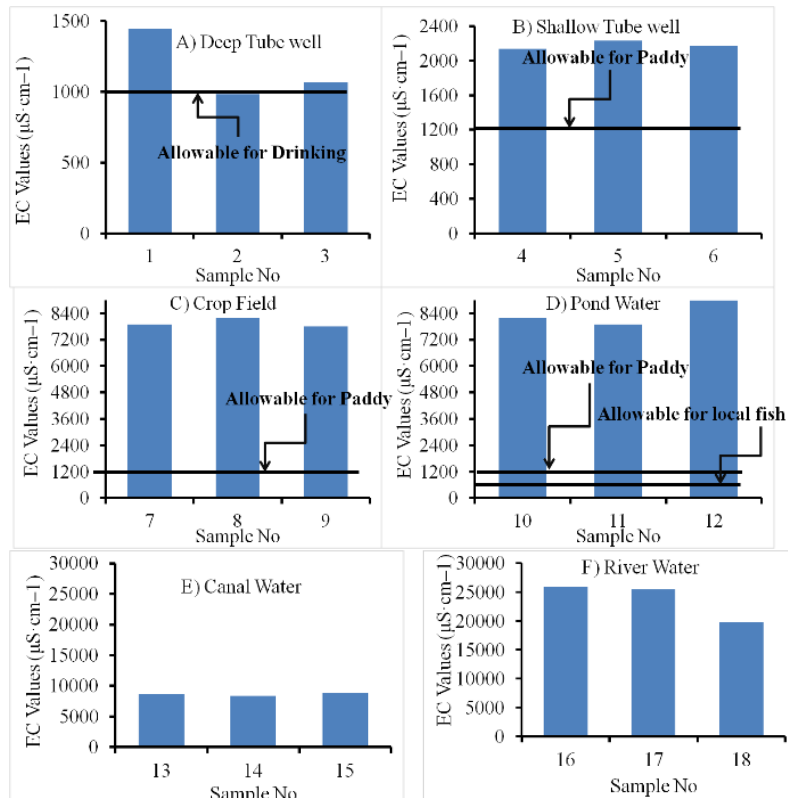

Fig. 6: EC Values of Water Collected from Different Location (As Shown Table 1). Solid Line Represents for Allowable Limit for Different Purpose.

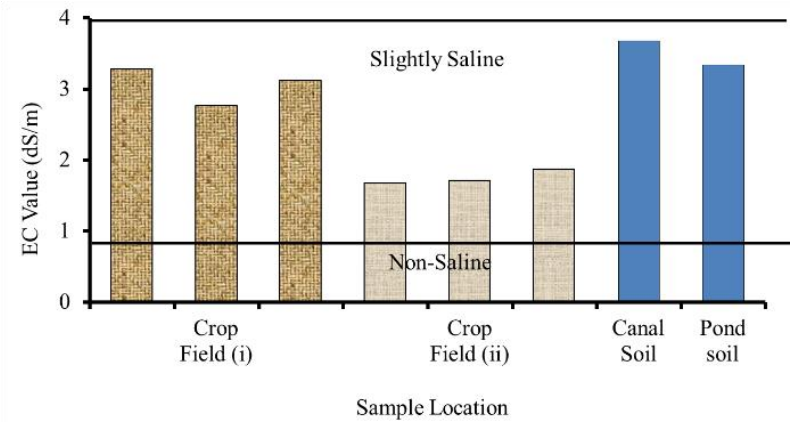

Fig. 7: EC Values of Soil Sample of Different Location (Left), Solid Line Represents Allowable Limit for Salinity.

\section{Discussion}

The Ganges and Gorai rivers discharge vary drastically due to implementation of various actives i.e. construction of Farakkah Barrage, shearing treaty, GRRP-I, GRRP-II which affect the salinity level of south-western coastal region of Bangladesh.

The water salinity level exceeded the allowable limit for irrigation and local fish in 2015. The GRRP-II was implemented in 2012, which may cause the salinity little low in 2015. As before the year 1999, it is obvious that the water and soil salinity of this region was much higher than the tolerable limit. This phenomenon is evident from the linear correlation analysis as well.

As the salinity variation of western coast is inversely proportional to the discharge of the Gorai river, minimum amount of discharge must be maintained to get suitable water for drinking, irrigation purposes as well as for the local fish survival. Fig. 5 shows that approximately a minimum discharge of $80 \mathrm{~m}^{3} / \mathrm{s}$ of the Gorai river at Railway bridge station would be required in the dry seasons to maintain a tolerable limit of salinity. To maintain approximately $80 \mathrm{~m}^{3} / \mathrm{s}$ discharges in the Gorai river, there should be approximately $1200 \mathrm{~m}^{3} / \mathrm{s} \mathrm{discharge}$ through the Ganges river at Harding bridge point. Before the second phase of GRRP, the discharges of both the rivers could not meet the minimum requirement in the dry seasons but after the second phase, the condition has been improved and the discharges have crossed the minimum values. So, it can be concluded that GRRP must be continued to ensure minimum required flow in the Gorai river. In addition, proper monitoring of the Ganges river sharing treaty should be performed to confirm the receiving amount of the Ganges river water from India. Without ensuring the upstream river flow, thinking of salinity minimization in the south-western coastal region of Bangladesh is meaningless.

\section{Conclusion}

The effects of salinity variation have become a vital issue for the south-western coastal region of Bangladesh. To identify the historical variation of salinity in response to upstream river discharge variation, analysis has been done based on the collected discharge data for the Ganges and Gorai river and salinity data for the Rupsha River.

The flow in dry seasons of the Ganges-Gorai river has been noticeably reduced since the construction of the upstream barrage; sequentially, salinity increased at the south-western region of Bangladesh. The improvement of the Ganges-Gorai river discharge due to the Ganges Water Sharing Agreement, GRRP-I and GRRP-II might help the region to improve the water and soil quality for irrigation and drinking purpose as well as for survival of local fish by reducing salinity level. The salinity level of collected water was in alarming level but soil sample was not in so frightening condition in 2015. This may be due to the implementation of GRRP-II. Thus, ensuring the upstream flow through the Ganges-Gorai river by executing projects like GRRP-I and GRRP-II may be the way of solution to save the south-western region from the adverse effects of salinity.

It can be concluded that the outcome of this study will encourage the researchers and policy makers to optimize flow augmentation in the Ganges-Gorai river to sustain the tolerable salinity level of western coast of Bangladesh in the future. 


\section{References}

[1] M. M. Q. Mirza, "Diversion of the Ganges water at Farakka and its effects on salinity in Bangladesh. Environ Manage.” Vol. 22, 711-722, 1998. https://doi.org/10.1007/s002679900141.

[2] G. Brij and M. Chauhan, "Biodiversity and its conservation in the Sundarbans Mangrove Ecosystem". Aquatic Science- Research across Boundaries, Vol. 68, 338-354, 2006. [3] A. Ahmadi, H. J. Mattausch, M. A. Abedin, T. Koide, Y. Shirakawa and A. Ritonga, "Developing a Reliable Learning Model for Cognitive Classification Tasks Using an Associative Memory," IEEE Symposium on Computational Intelligence in Image and Signal Processing (CIISP 2007), pp. 214-219, 2007.

[3] M. S. Iftekhar and M. R. Islam MR, "Managing mangroves in Bangladesh: A strategy analysis.” Journal of Coastal Conservation, Vol. 10, 139-146, 2004 https://doi.org/10.1007/BF02818950.

[4] M. Asafuddowla, "Farakka Issue. International Farakka Seminar," Columbia University, New York 1993.

[5] S. N Islam, A. Gnauck, "Threats to the Sundarbans mangrove wetland ecosystems from transboundary water allocation in the Ganges basin: A preliminary problem analysis". International Journal of Ecological Economic Statistics (IJEES), Vol. 13, 64-78.

[6] M. Rahman, V. R. Giedraitis, L. S. Lieberman and M. T. Akhter, "Shrimp Cultivation with Water Salinity in Bangladesh: The Implications of an Ecological Model." Universal Journal of Public Health, Vol. 1(3), 131-142, 2013.

[7] BECR. "The Bangladesh Environment Conservation Rules." 205-207, 1997.

[8] M. Ali, “Assessment of drinking water quality.” Journal of Ecology and Environmental Sciences. Vol. 5, 2017.

[9] ADB (Asian Development Bank), "Training manual for environmental monitoring." USA, Engineering Science Inc., 2-16, 1994.

[10] DoE (Department of Environment), "Bangladesh Gazette, No. DA-1.” Department of Environment. Ministry of Environment and Forest, 1324-1327, 1997.

[11] T. Biggs, and B. Pearce, "Soil Salinity and Exchangeable Cations in a Wastewater Irrigated Area, India." Journal of environmental quality, Vol. 38, 887-96, 2009. https://doi.org/10.2134/jeq2008.0247. 